\title{
Factors impacting patient cooperation during elective gastroscopy
}

\author{
Sang Pyo Lee, In-Kyung Sung, Jeong Hwan Kim, Sun-Young Lee, Hyung Seok Park, and Chan Sup Shim
}

Department of Internal Medicine, Konkuk University School of Medicine, Seoul, Korea

\author{
Received: December 5, 2015 \\ Revised : May 10, 2016 \\ Accepted: July 11, 2016

\section{Correspondence to} \\ In-Kyung Sung, M.D. \\ Department of Internal Medi- \\ cine, Digestive Disease Centre, \\ Konkuk University School of \\ Medicine, 120-1 Neungdong-ro, \\ Gwangjin-gu, Seoul 05030, Korea \\ Tel: +82-2-2030-5100 \\ Fax: +82-2-2030-7748 \\ E-mail: inksung@kuh.ac.kr
}

Background/Aims: Some people have difficulty tolerating upper endoscopy. The cause of and risk factors for this are not well known. The aim of this study was to investigate the factors involved in poor cooperation during screening upper endoscopy.

Methods: A total of 4,422 subjects who underwent a health inspection with upper endoscopy carried out by a single experienced endoscopist were included. We retrospectively investigated subjects' self-reporting questionnaires and medical records, including endoscopic and histologic findings. The examinees' cooperation and the completeness of endoscopic examination were evaluated based on the operator's subjective judgment.

Results: Examinee cooperation during the endoscopic procedure was poor in 358 out of 4,422 subjects (8.1\%). Of the subjects with poor cooperation, the endoscopic examination was incomplete in 36 subjects (10.1\%). Multivariate analysis revealed that young age (< 40 years), female sex, high body mass index $(\geq 25)$, hiatal hernia, and procedural sedation using midazolam were independent risk factors for poor cooperation.

Conclusions: Cooperation during screening upper endoscopy was poor in a considerable number of examinees. Endoscopists must keep in mind that examinee cooperation is more likely to be poor in the young, obese people, women, patients with hiatal hernias, and those who receive procedural sedation.

Keywords: Endoscopy; Poor cooperation; Hernia, hiatal; Procedural sedation

\section{INTRODUCTION}

Screening endoscopy in asymptomatic populations is widely performed worldwide, and it has been reported to help prevent gastric cancer [1]. However, some examinees experience difficulties in tolerating gastroscopy. In some cases, all parts of stomach cannot be observed for a sufficient time due to the examinee's poor cooperation. Furthermore, poor cooperation may increase the risk of complications after endoscopy and lower the detection rate of gastric lesions.

To date, few studies have been conducted to iden- tify the factors involved in poor cooperation during screening upper endoscopy. Only one previous study has been reported, which showed that age and anxiety significantly correlated with patient cooperation during endoscopy [2]. However, there may be a variety of factors affecting poor cooperation. Some people cannot suppress involuntary gagging even after pharyngeal anesthesia because of a sensitive gag reflex [3]. Others may fail to stifle a belch due to a large hiatal hernia $[4,5]$.

Procedural sedation during endoscopy can maximize patients' comfort and satisfaction $[6,7]$. The anterograde amnesic effect of midazolam makes the examinees un- 
able to recall painful memories of the procedure. However, it may reduce the examinee's cooperation during the procedure, because it is difficult to obey the operator's commands under sedation, and sometimes, paradoxical reactions to midazolam can develop [8]. In addition, many other factors may impact on the examinee's level of cooperation, including age, gender, underlying diseases, medication history, obesity, alcohol drinking, smoking, emotional stress, and depression.

Therefore, we investigated the factors that affect examinees' cooperation during screening upper endoscopy. In addition, we examined the effect of the examinee's cooperation on the completeness of the endoscopic examination and on complications after the procedure.

\section{METHODS}

\section{Patients and questionnaires}

We retrospectively reviewed the records of health examinations at Konkuk University Medical Center (Seoul, Korea), from September 2013 to April 2015. Among these, records of individuals over 18 years of age who underwent a gastroscopy were included in the study. To reduce the effect of variations between endoscopists, only gastroscopies carried out by a single experienced endoscopist (S.P.L.) were included. The study was approved by the Institutional Review Board (IRB) of Konkuk University School of Medicine, which confirmed that the study was in accordance with the ethical guidelines of the Helsinki Declaration (KUH1010664), and it was registered in the Clinical Research Information Service (CRIS) ID: KCTooo1512.

All the examinees filled out a self-reporting questionnaire, which included the following items: underlying disease, medication history, smoking, alcohol intake, dyspepsia symptoms, and levels of emotional stress and depression. Subjects' age, gender, height, weight, and endoscopic and histologic findings were also investigated. Heavy drinking was defined as consuming 15 drinks or more per week for men and eight drinks or more per week for women.

\section{Endoscopic procedure}

Gastroscopy was performed using a standard upper endoscope (GF-26o, Olympus, Tokyo, Japan; or EPK-I,
Pentax, Tokyo, Japan). Lidocaine spray was routinely used. All examinees provided written consent to undergo the endoscopic procedures. Midazolam for procedural sedation was selectively administered just before the start of the procedure in accordance with the examinee's preference. The usual starting dose for producing moderate sedation was 1 to $3 \mathrm{mg}$ based on age, gender, and medical conditions. The dose was increased to achieve an adequate level of sedation [6]. According to the American Society of Anesthesiologists guidelines, moderate sedation is defined as a state in which patients respond purposefully to verbal command and their cardiovascular function is maintained [9]. If a severe paradoxical reaction to midazolam occurred, it was immediately treated with flumazenil. If symptoms of midazolam overdose or midazolam side effects were noted, we tried to stabilize the vital signs of the patient first, and we considered the use of flumazenil. Symptoms of overdose or side effects included hypoxia, hypoventilation, hypotension, apnea, and central nervous system (CNS) depression. Oxygen supplementation was provided via a nasal cannula if the oxygen saturation level remained $<90 \%$, despite verbal and physical stimuli. Hypoxia was recorded only when supplemental oxygen was needed. The incidence of acute complications (abdominal pain, nausea, and vomiting) and late-onset complications (persisting throat pain, bowel perforation, and gastrointestinal [GI] bleeding) were investigated through chart review.

\section{Definitions and review of the endoscopic reports}

The examinee's cooperation and the completeness of endoscopic examination were evaluated by the operator's subjective judgment and recorded directly after the examination. Information on the level of cooperation was collected through a review of the endoscopic reports. "Poor cooperation" meant lack of cooperation of the examinees during the procedure regardless of one's will. The immediate causes of poor cooperation included severe belching, retching, coughing, and noncompliance of the examinees. "Belching" was defined as the forceful expulsion of gas from stomach through the mouth and "retching" was defined as an involuntary spasm of ineffectual vomiting. "Coughing" was defined as a sudden noisy expulsion of air from the bronchus or lungs, which is triggered by aspiration. "Non-compliance" referred to an action in contrast to bearing and 
managing impulses to enable the operator to perform the procedure. The study was considered incomplete when some parts of the stomach could not be sufficiently visualized during the procedure. The causes of incomplete study included poor cooperation and a large amount of food materials in the stomach.

Endoscopic and histologic records were reviewed to identify the presence of digestive diseases, such as peptic ulcer disease, reflux esophagitis, GI tract masses, nodular gastritis, chronic atrophic gastritis, and metaplastic gastritis. The endoscopic findings were described based on the criteria of the Sydney classification [10]. A diagnosis of erosive esophagitis was made in cases with hyperemic streaks or mucosal breaks on the lower esophagus. Minimal change lesions of the esophagus were excluded from this diagnosis. Peptic ulcer disease was diagnosed as a deep mucosal defect with evidence of submucosal invasion, excluding ulcer scars. Chronic atrophic gastritis was diagnosed when the mucosal and submucosal vessels were visible without full air distension [11]. Nodular gastritis was defined as chicken-skin like mucosal changes or unusual goose-flesh appearance, and metaplastic gastritis was defined as uneven, irregular whitish patches or plaques [12]. Diagnoses of adenoma and carcinoma were made based on the results of tissue biopsy.

\section{Depression and emotional stress}

Depression and emotional stress were assessed using the Korean version of the Beck's Depression Inventory (K-BDI) and the Brief Encounter Psychosocial Instrument-Korean version (BEPSI-K) [13,14]. The BEPSI-K consists of five self-administered items. A total score of o to 1.8 indicates a low level of stress; 1.8 to 2.8 , a moderate level of stress; and more than 2.8, a high level of stress. The cut off value of 2.4 as a significant stressful status was set based on previous studies $[15,16]$. The K$\mathrm{BDI}$ is a 21-item self-report questionnaire. A total score of o to 9 signifies no depression; 10 to 15 , mild depression; 16 to 23 , moderate depression; and 24 to 63 , severe depression. We considered a total score of $\geq 10$ as positive for depression.

\section{Definitions of functional dyspepsia}

Based on the Rome III definition, functional dyspepsia was diagnosed when the subjects had symptoms of dyspepsia without any evidence of reflux esophagitis, pep- tic ulcer disease, postoperative stomach, upper GI cancers, or any structural disease on upper GI endoscopy. Dyspepsia was defined as one or more of the following symptoms occurring at least once per week in the last 3 months: (1) bothersome postprandial fullness after ordinary-sized meals, (2) early satiety that prevents finishing a regular meal, and (3) epigastric pain or burning. Symptoms with an onset occurring more than 6 months prior to the survey were not asked about in our questionnaire.

\section{Statistical analysis}

Continuous variables and categorical variables were presented as mean \pm standard deviation (SD) and number (\%), respectively. Subjects were divided into the poor cooperation group and the good cooperation group, according to their level of cooperation during endoscopy. The characteristics of the two groups were compared using the chi-square test, Student $t$ test, and MannWhitney $U$ test. Logistic regression analyses were performed to estimate the odds ratio (OR) and 95\% confidence interval (CI) for factors that could result in poor cooperation during endoscopy. Statistical analyses were conducted using SPSS software version 19.0 (IBM Co., Armonk, NY, USA), and a $p<0.05$ was considered statistically significant in all tests.

\section{RESULTS}

\section{Baseline characteristics of the subjects}

A total of 4,422 subjects ( $56.5 \%$ male) were included in the study. The overall mean age and body mass index (BMI) were $45.19 \pm 9.87$ years (range, 18 to 86 ) and $23.57 \pm$ $3.27 \mathrm{~kg} / \mathrm{m}^{2}$ (range, 14.6 to 39.7 ), respectively (Table 1). The number of subjects who received sedation (midazolam) during endoscopy was 3,164 (71.6\%). Cooperation during the endoscopic procedure was poor in 358 subjects (8.1\%). The other characteristics of the study population are shown in Table 1.

\section{The poor cooperation and good cooperation groups}

In the poor cooperation group, the cause of poor cooperation was not recorded in 214 cases. Of the patients with causes recorded, the causes of poor cooperation were belching in 114 subjects (79.2\%), retching in 94 (65.3\%), non-compliance in 18 (12.5\%), and coughing in 
Table 1. Baseline characteristics of the subjects $(n=4,422)$

\begin{tabular}{|c|c|c|c|}
\hline Variable & No. (\%) & Mean \pm SD & Median (range) \\
\hline Age, yr & & $45.19 \pm 10.44$ & $44(18-86)$ \\
\hline Male sex & $2,498(56.5)$ & & \\
\hline $\begin{array}{l}\text { Body mass } \\
\text { index, } \mathrm{kg} / \mathrm{m}^{2}\end{array}$ & & $23.57 \pm 3.27$ & $23.31(14.6-39.7)$ \\
\hline$\geq 25$ & $1,339(30.4)$ & & \\
\hline$\geq 18.5$ and $<25$ & $2,882(65.5)$ & & \\
\hline$<18.5$ & $178(4 \cdot 1)$ & & \\
\hline K-BDI level & & $2.22 \pm 4.05$ & $0(0-46)$ \\
\hline No depression & $4,123(96.0)$ & & \\
\hline Mild & $96(2.2)$ & & \\
\hline Moderate & $61(1.4)$ & & \\
\hline Severe & $16(0.4)$ & & \\
\hline BEPSI-K level & & $1.61 \pm 0.83$ & $1.4(0-5)$ \\
\hline $\begin{array}{l}\text { Low level of } \\
\text { stress }\end{array}$ & $2,488(63.4)$ & & \\
\hline Moderate level & $931(23.7)$ & & \\
\hline High level & $508(12.9)$ & & \\
\hline \multicolumn{4}{|l|}{ Smoking } \\
\hline Non-smoker & $2,131(53.5)$ & & \\
\hline Past smoker & $1,004(25.2)$ & & \\
\hline Current smoker & $848(21.3)$ & & \\
\hline \multicolumn{4}{|l|}{ Alcohol } \\
\hline Non-drinker & $857(20.3)$ & & \\
\hline Social drinker & $3,224(76.3)$ & & \\
\hline Heavy drinker & $145(3.4)$ & & \\
\hline \multicolumn{4}{|l|}{ Comorbidity } \\
\hline Diabetes & $196(4.4)$ & & \\
\hline Hypertension & $543(12.3)$ & & \\
\hline $\begin{array}{l}\text { Congestive } \\
\text { heart disease }\end{array}$ & $68(1.5)$ & & \\
\hline Stroke & $5(0.1)$ & & \\
\hline \multicolumn{4}{|l|}{ Medication } \\
\hline $\begin{array}{l}\text { Antiplatelet } \\
\text { agent }\end{array}$ & $76(1.7)$ & & \\
\hline Anticoagulant & $6(0.1)$ & & \\
\hline NSAID & $226(5.1)$ & & \\
\hline Antidepressant & $22(0.5)$ & & \\
\hline $\begin{array}{l}\text { Herb and } \\
\text { health food }\end{array}$ & $750(17.0)$ & & \\
\hline $\begin{array}{l}\text { Symptoms of } \\
\text { dyspepsia }\end{array}$ & $691(16.6)$ & & \\
\hline $\begin{array}{l}\text { Postprandial } \\
\text { fullness }\end{array}$ & $470(11.3)$ & & \\
\hline Early satiety & $280(6.7)$ & & \\
\hline
\end{tabular}

Table 1. Continued

\begin{tabular}{lccc}
\hline Variable & No. $(\%)$ & Mean \pm SD & Median(range) \\
\hline $\begin{array}{l}\text { Epigastric pain/ } \\
\text { burning }\end{array}$ & $218(5.2)$ & & \\
$\begin{array}{l}\text { Procedural } \\
\text { sedation }\end{array}$ & $3,164(71.6)$ & & \\
Dose of & & $3.69 \pm 0.67$ & $4(1-7)$ \\
midazolam, mg & & & \\
$\begin{array}{l}\text { Poor cooperation } \\
\text { during }\end{array}$ & $358(8.1)$ & & \\
endoscopy & & & \\
\hline
\end{tabular}

BMI, K-BDI, BEPSI-K, smoking, drinking, and dyspepsia symptoms were not properly measured in 23, 126, 495, 439, 196, and 250 subjects, respectively.

$\mathrm{SD}$, standard deviation; K-BDI, Korean version of the Beck's Depression Inventory; BEPSI-K, The Brief Encounter Psychosocial Instrument-Korean version; NSAID, nonsteroidal anti-inflammatory drug.

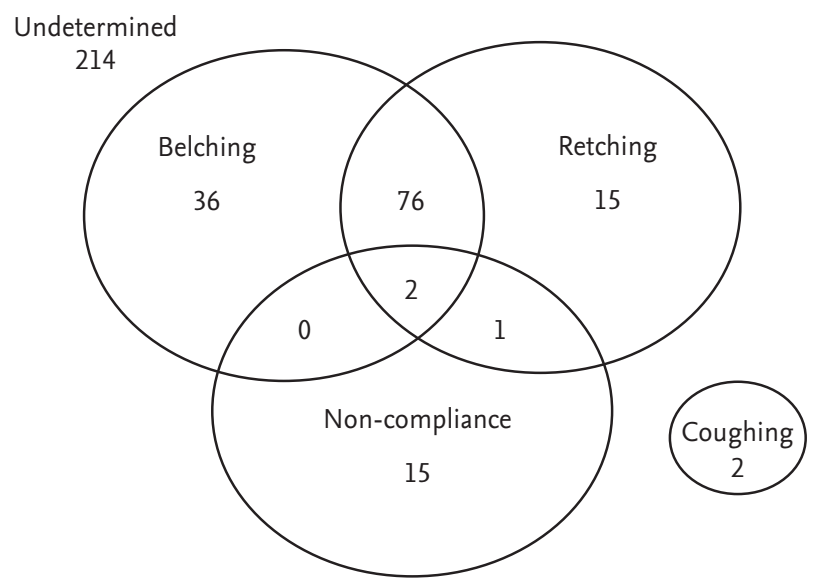

Figure 1. Venn diagram of the causes of poor cooperation. In 214 subjects, the causes of poor cooperation were not recorded. After their exclusion, the causes of poor cooperation were belching in 114 subjects (79.2\%), retching in 94 (65.3\%), non-compliance in 18 (12.5\%), and coughing in two (1.4\%). Poor cooperation was often caused by multiple reasons (79 subjects, 54.9\%). Belching and retching frequently occurred together.

two (1.4\%) (Fig. 1). Often, poor cooperation was caused by multiple reasons (79 subjects, 54.9\%).

Poor cooperation was more common among younger subjects and in women $(p<0.001$ and $p=0.003$, respectively) (Table 2). When broken down by age group, cooperation was poor in $9.6 \%$ of those in their 20 s or younger (18 of 187), $10.5 \%$ of those in their 30 (123 of 1,174), $7.9 \%$ of 
Table 2. Comparison between the poor cooperation and good cooperation group

\begin{tabular}{|c|c|c|c|}
\hline Variable & $\begin{array}{l}\text { Poor cooper- } \\
\text { ation group } \\
\left(\mathrm{n}=35^{8}\right)\end{array}$ & $\begin{array}{l}\text { Good coop- } \\
\text { eration group } \\
(n=4,064)\end{array}$ & $p$ value \\
\hline $\mathrm{Age}^{\mathrm{a}}, \mathrm{yr}$ & $43.40 \pm 9.87$ & $45.35 \pm 10.48$ & $<0.001^{b}$ \\
\hline$<40$ & $141(39.4)$ & $1,220(30.0)$ & $<0.001^{\mathrm{b}}$ \\
\hline Female sex & $183(51.1)$ & $1,741(42.8)$ & $0.003^{b}$ \\
\hline $\begin{array}{l}\text { Body mass index }{ }^{\mathrm{a}} \text {, } \\
\mathrm{kg} / \mathrm{m}^{2}\end{array}$ & $24.17 \pm 3.37$ & $23.52 \pm 3.25$ & $0.001^{b}$ \\
\hline$\geq 25$ & $130(36.6)$ & $1,209(29.9)$ & $0.010^{b}$ \\
\hline Smoking & & & $0.049^{b}$ \\
\hline Non-smoker & $188(57 \cdot 7)$ & $1,943(53 \cdot 1)$ & \\
\hline Past smoker & $64(19.6)$ & $940(25 \cdot 7)$ & \\
\hline Current smoker & $74(22.7)$ & $774(21.2)$ & \\
\hline Alcohol & & & 0.306 \\
\hline Non-drinker & $78(22.5)$ & $779(20.1)$ & \\
\hline Social drinker & $260(75.1)$ & $2,964(76.4)$ & \\
\hline Heavy drinker & $8(2.3)$ & $137(3.5)$ & \\
\hline \multicolumn{4}{|l|}{ Medication } \\
\hline Antidepressant & o & $22(0.5)$ & 0.252 \\
\hline NSAID & $21(5 \cdot 9)$ & $205(5.0)$ & 0.530 \\
\hline K-BDI level $\geq 10$ & $19(5.4)$ & $154(3.9)$ & 0.200 \\
\hline BEPSI-K level $\geq 2.4$ & $62(19.4)$ & $710(19 \cdot 7)$ & 0.946 \\
\hline $\begin{array}{l}\text { First-time } \\
\text { endoscopy }\end{array}$ & $27(8.1)$ & $341(9.0)$ & 0.618 \\
\hline $\begin{array}{l}\text { Procedural } \\
\text { sedation }\end{array}$ & $316(88.3)$ & $2,848(70.1)$ & $<0.001^{b}$ \\
\hline \multicolumn{4}{|c|}{ Midazolam side effect } \\
\hline Hypotension & o & 1 & \\
\hline Hypoxia & 15 & 128 & \\
\hline Use of flumazenil & 10 & 1 & \\
\hline \multicolumn{4}{|l|}{ Digestive diseases } \\
\hline $\begin{array}{l}\text { Functional } \\
\text { dyspepsia }\end{array}$ & $47(13.9)$ & $595(15 \cdot 5)$ & 0.434 \\
\hline Nodular gastritis & $3(0.8)$ & $44(1.1)$ & 1.000 \\
\hline $\begin{array}{l}\text { Chronic } \\
\text { Atrophic gastritis }\end{array}$ & $215(60.1)$ & $2,350(57.8)$ & 0.434 \\
\hline $\begin{array}{l}\text { Metaplastic } \\
\text { gastritis }\end{array}$ & $23(6.4)$ & $240(5 \cdot 9)$ & 0.726 \\
\hline Reflux esophagitis & $22(6.1)$ & $209(5.1)$ & 0.456 \\
\hline $\begin{array}{l}\text { Peptic ulcer } \\
\text { disease }\end{array}$ & $5(1.4)$ & $88(2.2)$ & 0.353 \\
\hline $\begin{array}{l}\text { Postoperative } \\
\text { stomach }\end{array}$ & $1(0.3)$ & $15(0.4)$ & 1.000 \\
\hline $\begin{array}{l}\text { Gastric } \\
\text { adenocarcinoma }\end{array}$ & o & 4 & 1.000 \\
\hline
\end{tabular}

Table 2. Continued

\begin{tabular}{|cccc}
\hline Variable & $\begin{array}{c}\text { Poor cooper- } \\
\text { ation group } \\
(\mathrm{n}=358)\end{array}$ & $\begin{array}{c}\text { Good coop- } \\
\text { eration group } \\
(\mathrm{n}=4,064)\end{array}$ & p value \\
\hline Gastric adenoma & 0 & 6 & 1.000 \\
\hline Hiatal hernia & $19(5.3)$ & $118(2.9)$ & $0.017^{\mathrm{b}}$ \\
\hline Complications & $3(0.8)$ & $12(0.3)$ & 0.116 \\
\hline $\begin{array}{l}\text { Persisting } \\
\text { throat pain }\end{array}$ & 2 & 8 & \\
\hline GI bleeding & 0 & & \\
\hline $\begin{array}{c}\text { Bowel perforation } \\
\text { Abdominal pain }\end{array}$ & 0 & 0 & \\
\hline Nausea/Vomiting & 0 & 0 & \\
\hline Incomplete study & $36(10.1)$ & $8(0.2)$ & $<0.001^{\mathrm{b}}$ \\
\hline $\begin{array}{c}\text { Due to poor } \\
\text { cooperation }\end{array}$ & 36 & 0 & \\
\hline $\begin{array}{l}\text { Due to food } \\
\text { materials }\end{array}$ & 0 & 8 & \\
\hline
\end{tabular}

Values are presented as mean $\pm \mathrm{SD}$ or number (\%).

NSAID, nonsteroidal anti-inflammatory drug; K-BDI, Korean version of the Beck's Depression Inventory; BEPSI-K, The Brief Encounter Psychosocial Instrument-Korean version. ${ }^{a}$ Continuous variables were analyzed by the Mann-Whitney test. All other data were analyzed by the chi-square test.

${ }^{\mathrm{b}_{\mathrm{T}}}$ The significant results.

those in their $40 \mathrm{Os}$ (134 of 1,702), $6.2 \%$ of those in their $50 \mathrm{~s}$ (60 of 968 ), 5.9\% of those in their 6os (17 of 287 ), and 5.8\% of those in their 7os or older (six of 104) (Fig. 2). Subjects in the poor cooperation group had a higher proportion of non-smokers and a lower proportion of past smokers $(p=0.049)$. Poor cooperation was also related to a high BMI, hiatal hernia, and procedural sedation $(p=0.001, p$ $=0.017$, and $p<0.001$, respectively). Emotional stress, depression, functional dyspepsia, alcohol intake, and medication history were not related with poor cooperation.

Among the subjects who received procedural sedation, $10(3.2 \%)$ in the poor cooperation group and one in the good cooperation group were administered the antidote (flumazenil). In the good cooperation group, the reason for using the antidote was hypoxia that could not be alleviated with nasal cannula oxygenation. Three subjects in the poor cooperation group and 12 subjects in the good cooperation group developed complications after the procedure, with no significant difference between the two groups $(p=0.116)$. The endoscopic exam- 
ination of 44 subjects was an "incomplete study." The causes of incomplete study were poor cooperation in 36 cases and large amounts of food materials in the stomach in eight cases.

\section{Predisposing factors for examinees' poor cooperation} Logistic regression analysis revealed that that young age (<40 years) and female sex were independent predisposing factors for an examinee's poor cooperation during upper endoscopy (OR, 1.423; 95\% CI, 1.125 to $1.801 ; p=$

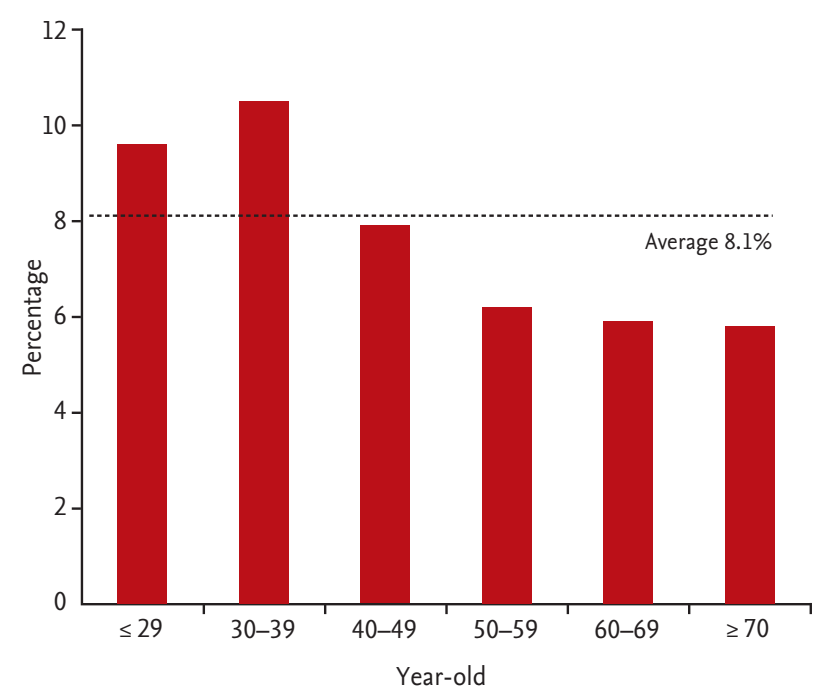

Figure 2. Percentages of subjects with poor cooperation by age group. Examinees' cooperation was poor in $9.6 \%$ of those in their 20 s or younger (18 of 187 ), $10.5 \%$ of those in their $30 \mathrm{OS}$ (123 of 1,174), 7.9\% of those in their $40 \mathrm{OS}$ (134 of 1,702), $6.2 \%$ of those in their $50 \mathrm{Os}$ (60 of 968), 5.9\% of those in their $60 \mathrm{~s}$ (17 of 287), and 5.8\% of those in their 7os or older (six of 104). Among the subjects under 40 , the percentage of subjects with poor cooperation was above average.
0.003) (OR, 1.670; 95\% CI, 1.216 to $2.294 ; p=0.002$ ) (Table 3). In addition, high BMI ( $\geq 25)$, hiatal hernia, and procedural sedation were also independent predisposing factors for poor cooperation (OR, 1.501; 95\% CI, 1.165 to $1.935 ; p=0.002)(\mathrm{OR}, 2.235 ; 95 \% \mathrm{CI}, 1.300$ to $3.844 ; p=$ $0.004)(\mathrm{OR}, 2.918 ; 95 \% \mathrm{CI}, 2.083$ to $4.088 ; p<0.001)$. After logistic analysis, smoking history was not related with examinees' poor cooperation.

\section{DISCUSSION}

Our study showed that $8.1 \%$ of examinees cooperated poorly with elective gastroscopy. This indicates that a considerable number of examinees have difficulty when undergoing gastroscopy. The main predisposing factor for poor cooperation was sedation using midazolam. The risk of poor cooperation in subjects who received sedation was three times higher than that in subjects who did not receive sedation. Sedation can assuage patients' fears about receiving endoscopy and maximize patient comfort during the procedure $[6,7,9]$. However, a patient under sedation may not be able to obey the doctor's commands. For example, when patients cannot suppress a belch during endoscopy, doctor can instruct them to hold their breath for a while. Likewise, doctor can direct not to swallow saliva to prevent coughing. However, it is difficult for patients under sedation to carry out the instructions because of altered level of consciousness. In addition, paradoxical reactions to midazolam can sometimes develop. Therefore the outcome of previous endoscopic examinations should be examined to decide whether sedation is performed. If

Table 3. Univariate and multivariate models of the predictors of examinee's poor cooperation during endoscopic procedure

\begin{tabular}{|c|c|c|c|c|}
\hline \multirow{2}{*}{ Variable } & \multicolumn{2}{|c|}{ Univariate analysis } & \multicolumn{2}{|c|}{ Multivariate analysis } \\
\hline & OR (95\% CI) & $p$ value & Adjusted OR (95\% CI) & $p$ value \\
\hline Age $<40$ & $1.515(1.213-1.892)$ & $<0.001$ & $1.423(1.125-1.801)^{\mathrm{a}}$ & $0.003^{\mathrm{a}}$ \\
\hline Female sex & $1.395(1.124-1.732)$ & 0.003 & $1.670(1.216-2.294)^{\mathrm{a}}$ & $0.002^{\mathrm{a}}$ \\
\hline Body mass index $\geq 25$ & $1.355(1.081-1.355)$ & 0.008 & $1.501(1.165-1.935)^{\mathrm{a}}$ & $0.002^{\mathrm{a}}$ \\
\hline Hiatal hernia & $1.874(1.140-3.081)$ & 0.013 & $2.235(1.300-3.844)^{\mathrm{a}}$ & $0.004^{\mathrm{a}}$ \\
\hline Procedural sedation & $3.212(2.312-4.463)$ & $<0.001$ & $2.918(2.083-4.088)^{a}$ & $<0.001^{\mathrm{a}}$ \\
\hline Non-smoker & $1.202(0.956-1.511)$ & 0.116 & - & - \\
\hline
\end{tabular}

OR, odds ratio; CI, confidence interval.

${ }^{a}$ Univariate and multivariate logistic regression analyses were performed and footnotes are placed at the significant results. 
the examinee's cooperation was very poor in a previous endoscopy procedure under sedation, endoscopy without sedation should be considered.

Young age and female sex were predisposing factors for poor cooperation. Young people may not be able to suppress involuntary gagging due to a more sensitive gag reflex [3]. Gender differences in pain sensitivity have become a focus of clinical interest in recent decades. Previous studies revealed that postoperative and procedural pain may be more severe among female than among male individuals [17]. In addition, women have lower visceral pain thresholds [18].

Hiatal hernia and obesity were also significantly associated with poor cooperation. People with a hiatal hernia may fail to stifle a belch during the endoscopic procedure, which can interrupt observation. Obesity can cause hiatal hernia $[5,19,20]$. However, regardless of the existence of hiatal hernia, obesity can increase intra-abdominal pressure, and the increased pressure can obstruct air inflation during endoscopy [19]. Thus it can prevent the stomach from expanding and interrupt observation. Although overall, the majority of females, young people, obese people, and people with hiatal hernias underwent endoscopy relatively well in our study, before performing the procedure in these patients, endoscopists should keep in mind that cooperation may be poor.

The causes of poor cooperation in this study were diverse, including belching, retching, non-compliance, and coughing. However, it was often caused by several factors, meaning that sometimes a cause cannot be determined. Belching and retching especially often occurred together. In practice, however, it is difficult to distinguish belching from retching in many cases. Noncompliance can be caused by anxiety related to fear or to paradoxical reactions to midazolam. If a paradoxical reaction was suspected during endoscopy, antidote was administered without delay. In our study, 10 examinees received flumazenil due to non-compliance, in all of whom the endoscopic examination was finished safely.

The manifestations of midazolam overdose or side effects include hypoxia, hypoventilation, hypotension, apnea, and CNS depression [6]. In our study, there were few severe symptoms of overdose or side effect, and the most common symptom that occurred was hypoxia. Most cases of hypoxia resolved with conservative treat- ment, with only one case requiring the use of flumazenil because of hypoxia.

Our study showed that about 10\% of endoscopic examinations in the poor cooperation group were incomplete. In addition, cases of adenoma and adenocarcinoma were not detected in the poor cooperation group. Although the sample size was small, these results revealed that the examinee's poor cooperation can interfere with adequate stomach observation.

This study has some limitations. First, the endoscopist's judgment of poor cooperation is bound to be subjective. We therefore investigated the records of procedures performed by only one endoscopist to minimize bias and inter-individual variance of endoscopists. Second, some procedural complications may have been overlooked. Mild oral bleeding or throat pain after the procedure might not be included in a patient's record, because the examinees can leave the hospital without complaint. Third, there were some missing values. The BMI of 23 subjects, K-BDI of 126 subjects, BEPSI-K of 495 subjects, smoking history of 439 subjects, drinking status of 196 subjects, and dyspepsia symptoms of 250 subjects were not measured or were not recorded. The cause of poor cooperation was also not recorded in 214 subjects. Lastly, although we measured the level of emotional stress and depression, which had no effect on the examinee's cooperation, the anxiety level of the examinees was not measured.

In conclusion, cooperation during elective gastroscopy was poor in a considerable number of examinees. Poor cooperation did not lead to more frequent complications but could sometimes cause incomplete study. Endoscopists must keep in mind that cooperation is more likely to be poor in young people, obese people, women, those with hiatal hernia, and those who received sedation during the examination.

\section{KEY MESSAGE}

1. Cooperation during gastroscopy is poor in a considerable number of examinees and poor cooperation sometimes causes incomplete study.

2. Cooperation during gastroscopy is more likely to be poor in young people, obese people, women, those with hiatal hernia, and those who received sedation. 


\section{Conflict of interest}

No potential conflict of interest relevant to this article was reported.

\section{REFERENCES}

1. Dan YY, So JB, Yeoh KG. Endoscopic screening for gastric cancer. Clin Gastroenterol Hepatol 2006;4:709-716.

2. Mahajan RJ, Johnson JC, Marshall JB. Predictors of patient cooperation during gastrointestinal endoscopy. J Clin Gastroenterol 1997;24:220-223.

3. Evans LT, Saberi S, Kim HM, Elta GH, Schoenfeld P. Pharyngeal anesthesia during sedated EGDs: is "the spray" beneficial? A meta-analysis and systematic review. Gastrointest Endosc 2006;63:761-766.

4. Roman S, Kahrilas PJ. The diagnosis and management of hiatus hernia. BMJ 2014;349:g6154.

5. Menon S, Trudgill N. Risk factors in the aetiology of hiatus hernia: a meta-analysis. Eur J Gastroenterol Hepatol 2011;23:133-138.

6. Cohen LB, Delegge MH, Aisenberg J, et al. AGA Institute review of endoscopic sedation. Gastroenterology 2007;133:675-701.

7. Standards of Practice Committee of the American Society for Gastrointestinal Endoscopy, Lichtenstein DR, Jagannath $\mathrm{S}$, et al. Sedation and anesthesia in GI endoscopy. Gastrointest Endosc 2008;68:815-826.

8. Triantafillidis JK, Merikas E, Nikolakis D, Papalois AE. Sedation in gastrointestinal endoscopy: current issues. World J Gastroenterol 2013;19:463-481.

9. American Society of Anesthesiologists Task Force on Sedation and Analgesia by Non-Anesthesiologists. Practice guidelines for sedation and analgesia by non-anesthesiologists. Anesthesiology 2002;96:1004-1017.

10. Tytgat GN. The Sydney System: endoscopic division. En- doscopic appearances in gastritis/duodenitis. J Gastroenterol Hepatol 1991;6:223-234.

11. Nomura S, Ida K, Terao S, et al. Endoscopic diagnosis of gastric mucosal atrophy: multicenter prospective study. Dig Endosc 2014;26:709-719.

12. Ahn SY, Lee SY, Hong SN, et al. Endoscopic diagnosis of open-type atrophic gastritis is related to the histological diagnosis of intestinal metaplasia and Cdx2 expression. Dig Dis Sci 2011;56:1119-1126.

13. Frank SH, Zyzanski SJ. Stress in the clinical setting: the Brief Encounter Psychosocial Instrument. J Fam Pract 1988;26:533-539.

14. Beck AT, Ward CH, Mendelson M, Mock J, Erbaugh J. An inventory for measuring depression. Arch Gen Psychiatry 1961;4:561-571.

15. Lee SP, Sung IK, Kim JH, Lee SY, Park HS, Shim CS. The effect of emotional stress and depression on the prevalence of digestive diseases. J Neurogastroenterol Motil 2015;21:273-282.

16. Song EM, Jung HK, Jung JM. The association between reflux esophagitis and psychosocial stress. Dig Dis Sci 2013;58:471-477.

17. Fillingim RB, King CD, Ribeiro-Dasilva MC, Rahim-Williams B, Riley JL 3rd. Sex, gender, and pain: a review of recent clinical and experimental findings. J Pain 2009;10:447-485.

18. Arendt-Nielsen L, Bajaj P, Drewes AM. Visceral pain: gender differences in response to experimental and clinical pain. Eur J Pain 2004;8:465-472.

19. Pandolfino JE, El-Serag HB, Zhang Q, Shah N, Ghosh SK, Kahrilas PJ. Obesity: a challenge to esophagogastric junction integrity. Gastroenterology 2006;130:639-649.

20. Wilson LJ, Ma W, Hirschowitz BI. Association of obesity with hiatal hernia and esophagitis. Am J Gastroenterol 1999;94:2840-2844. 